\title{
The Impact of Resource Loss and Traumatic Growth on Probable PTSD and Depression Following Terrorist Attacks
}

\author{
Stevan E. Hobfoll \\ The Applied Psychology Center, Kent State University, Kent, OH 44242-0001 and Department \\ of Psychiatry, Summa Health System, Akron, OH 44310 \\ Melissa Tracy and Sandro Galea \\ Department of Epidemiology, School of Public Health, The University of Michigan, Ann Arbor, \\ MI 48104-2548
}

\begin{abstract}
The authors interviewed by phone 2,752 randomly selected individuals in New York City within 6 to 9 months after the attacks of September 11, 2001 on the World Trade Center, and 1,939 of these were reinterviewed at a 12- to 16-month follow-up. It was hypothesized that resource loss would significantly predict probable posttraumatic stress disorder (PTSD) and probable depression since September 11, and that resource loss's impact would be independent of previously identified predictors relating to individuals' demographic characteristics, history of stressful event exposure, prior trauma history, peritraumatic experience, and social support. Second, it was predicted that reported traumatic growth would be related to greater, not lesser, psychological distress. The authors' findings supported their hypotheses for resource loss, but traumatic growth was unrelated to psychological outcomes when other predictors were controlled.
\end{abstract}

The attacks of September 11, 2001 on the World Trade Center (WTC) in New York City (NYC) represented the largest terrorist attack in U.S. history. The attacks brought significant loss of life with 2,749 killed, $\$ 21.8$ billion estimated destruction of property, and loss of an estimated 146,000 people's livelihoods (New York City Department of Health and Mental Hygiene, 2003; New York City Office of the Comptroller, 2002). Several studies have examined the psychological impact of the attacks of September 11th (Galea et al., 2002; Schlenger et al., 2002), and all have documented substantial psychological consequences among those who were directly or indirectly exposed to the attacks. It is also notable that the initial high levels of psychological distress largely diminished within a 6month to 1-year period (Galea et al., 2003), consistent with prior research on the impact of war on civilians in Israel (Hobfoll, Lomranz, Eyal, Bridges, \& Tzemach, 1989; Lomranz, Hobfoll, Johnson, Eyal, \& Zemach, 1994). Nevertheless, long-term distress has been documented in a substantial proportion of residents of the NYC metropolitan area and there is both theoretical and applied interest in understanding the origins and nature of these long-term effects (Galea et al., 2002; Schlenger et al., 2002).

Research on the impact of the events of September 11th has been largely atheoretical. Most research identifying risk and, to a lesser extent, resiliency factors associated with

Correspondence concerning this article should be addressed to Stevan Hobfoll, The Applied Psychology Center, Kent State University, 106 Kent Hall, P.O. Box 5190, Kent, OH 44242-0001. E-mail: shobfoll@kent.edu. 
psychological sequelae following the attacks has been based on prior empirical findings and on using statistical tests of association to identify key risk factors from long lists of potential determinants. Such research may well lead to the development of new theoretical models, but we would argue that theoretical models already exist that can contribute to our understanding of the impact of terrorism. Two models, in particular, have been used to understand the impact of terrorism and disasters. The first, which we will not study here but need to mention, is the clinical model. The clinical model suggests that those with former psychopathology, including history of posttraumatic stress disorder (PTSD), depression, anxiety disorders, and substance abuse disorders are more vulnerable to new trauma because of their latent emotionality and inability to handle the considerable demand that follows terrorism or disaster (Franklin, Young, \& Zimmerman, 2002). The second model that has shown increasing promise in understanding the impact of disaster, war, and terrorism is the conservation of resources (COR) theory (Hobfoll, 1989, 1998, 2001). This study is based on COR theory and is the first study directly applying COR theory to the investigation of the impact of the events of September 11 in NYC. It also is the first to examine how resource loss and resource gain predict psychological sequelae of mass trauma over and above the effect of other known indicators of PTSD and depression (e.g., prior trauma history, peritraumatic reactions, etc.).

The COR theory (Hobfoll, 1989, 2001) posits that resource loss is the major factor in predicting psychological impact of stressful events. Resources have been defined as those objects, personal characteristics, conditions, or energies that are valued in their own right or that are valued because they act as conduits to the achievement or protection of valued resources (Diener \& Fujita, 1995; Hobfoll, 1988). A focus on resource loss suggests that life events, as a broad category, are too undifferentiated as units of analysis (Sattler et al., 2002). For this reason, recent research on stress has increasingly focused on unpacking stressful events into smaller components that contextualize what occurred (Dohrenwend, Raphael, Schwartz, Stueve, \& Skodol, 1993; Freedy, Saladin, Kilpatrick, Resnick, \&
Saunders, 1994; Sattler et al., 2002), and unpacking events into resource losses and gains is one such strategy.

Disasters, like terrorism, often are large-scale, beyond individuals' control, and lead to major resource loss. Studies carried out after disasters have found that resource loss is a key predictor of psychological distress. Examining Hurricane Andrew, the most devastating hurricane to hit the American mainland prior to Katrina, studies (Benight et al., 1999; Ironson et al., 1997) found that resource loss was the best predictor of PTSD, general psychological distress, and intrusive thoughts. It was also the only predictor of immune compromise (Ironson et al., 1997). Studies of war and disaster further support COR theory. They note that initial resource loss is likely to contribute to long-term loss cycles, which translate to ongoing difficulties in recovery (King, King, Foy, Keane \& Fairbank, 1999; Norris \& Kaniasty, 1996). In this manner, those who have the fewest resources are most affected in the crisis stage, have fewer resources for recovery, and continue to be vulnerable to the further demands that follow in the aftermath of disaster, terrorism, and war.

The COR theory originally posited that resource gains would have a beneficial impact during the stress process and would be associated with lower levels of psychological distress. Further, it was initially theorized and found that the impact of resource loss would far outweigh the impact of resource gain (Hobfoll, 1989; 1998; Wells, Hobfoll, \& Lavin, 1999). Recently, interest has turned to the role of resource gains, specifically gains related to exposure to traumatic events. This has been termed traumatic growth (Tedeschi \& Calhoun, 1995). Several studies show traumatic growth to be associated with greater well-being (Ai, Cascio, Santangelo, \& Evans-Campbell, 2005; Frazier, Conlon, \& Glaser, 2001). However, other studies find that traumatic growth and psychological distress exist on separate dimensions, and are independent of one another (Tedeschi \& Calhoun, 2004). Still other studies have noted that perceived resource gains in the sense of meaning and intimacy following trauma (i.e., traumatic growth) may in some instances be related to a greater burden of psychological distress (Hobfoll, Canetti-Nisim, \& Johnson, 2006; Tomich \& Helgeson, 2004). 
The question arises as to why traumatic growth may have these rather paradoxical negative effects in some instances. One possibility is that such reports of traumatic growth (i.e., resource gains associated with traumatic events) in some instances may be an attempt at emotion-focused coping that might forestall active coping efforts. In this regard, Ross and his colleagues (Ross, 1989; Wilson \& Ross, 2001) suggest that individuals derogate past selves through self-enhancement to maintain positive views of their current selves. In this way, posttraumatic growth may serve the protective function of enabling favorable comparisons of the pretrauma and posttrauma selves to bolster feelings of mastery and selfefficacy, but not be related to actual mastering of life challenges and recovery. In this study, we systematically assess the contribution of both resource loss and resource gain to the development of psychopathology after a terrorist attack.

In examining the impact of resource loss and gain following a terrorist attack, it would be important to show that resource loss and gain impact individuals independent of other known risk factors. In this regard, important risk factors have been identified and already reported for residents of Manhattan following September 11th (Galea et al., 2002; 2003). One domain of important risk factors relates to degree of exposure to stressors, indicating the degree to which individuals' resources are already being challenged (Hobfoll, 1988, 1998; Lazarus \& Folkman, 1984). Degree of stress exposure may be represented by proximity to the attack, prior trauma exposure, other trauma exposure since September 11th and general exposure to major (nontraumatic) stressors (Brewin, Andrews, \& Valentine, 2000; Galea et al., 2002). A second risk factor is having a panic reaction during the time of the attacks, which is an indication of degree of psychological vulnerability shown at the time of trauma exposure (Nixon, Resick, \& Griffin, 2004). Another important domain of risk factors relates to social and sociological risk factors. These include ethnic minority status, female gender, lower education, and lower income (Brewin et al., 2000). Income, education, and minority status are believed to impact vulnerability in complex fashions that have been related to overall life de- mands, knowledge about coping, and access to social and material resources (Dohrenwend \& Dohrenwend, 1981; Hobfoll, 1998). Female gender is seen as a risk factor owing to differences in ways men and women process emotions (Breslau, Davis, Andreski, Peterson, \& Schultz, 1997; Bryant \& Harvey, 2003). Finally, those with greater social support have been found to be at reduced risk for psychological distress following trauma because of both emotional and instrumental support they receive that counteracts the negative emotions and negative life circumstances that accompany trauma (Brewin et al., 2000; Norris, Baker, Murphy \& Kaniasty, 2005; Norris \& Kaniasty, 1996). Again, our major purpose was to examine to what extent resource loss and gain impacted individuals over and above the impact of these known risk factors, not to explore the risk factors themselves in detail.

\section{HYPOTHESES}

Based on our review of the literature we posit three hypotheses. First, we hypothesize that resource loss will significantly predict psychological distress, in the form of probable PTSD and probable depression, during the year following September 11, 2001 among those potentially exposed to the WTC attacks. We hypothesize that the impact of resource loss will be evidenced independently of previously identified predictors relating to individuals' demographic characteristics, history of stressful event exposure, prior trauma history, peritraumatic experience, and social support. Second, we hypothesize that resource gain in the form of finding greater meaning and intimacy (e.g., traumatic growth) as a result of the attacks of September 11 will be related to greater, not lesser, psychological distress during the year following September 11, 2001. Finally, we hypothesize that the impact of resource loss will exceed the impact of resource gain. We focus here on PTSD and depression; both disorders highly impair functioning, are experienced as painful and distressing, and have been linked to exposure to environmental stressors (Galea et al., 2002, 2003). 


\section{METHOD}

\section{Participants}

Data for this analysis comes from the baseline and first follow-up interviews of a cohort of persons who were living in the NYC metropolitan area on September 11, 2001. Participants for the cohort were recruited through a random-digit dial household survey conducted between March 25, 2002 and June 25, 2002. The sampling frame for the survey consisted of all adults in the NYC metropolitan area (approximately 13.5 million people). Households were screened for eligibility by location. If eligible, an adult in each household was randomly selected to complete the interview by choosing the adult whose birthday was closest to the interview date. Up to 10 attempts were made to conduct the interview. All interviews were conducted by trained interviewers in English, Spanish, Mandarin, and Cantonese, using questionnaires that were translated and back-translated by qualified translators, and a computerassisted telephone interview system. Questionnaires were translated and back translated by fully fluent experts. The overall response rate among persons eligible for the survey was $56 \%$. Additional details on the recruitment of the baseline sample can be found elsewhere (Galea et al., 2003, 2004).

Contact information was obtained for respondents and their key family members, and the first follow-up interview was conducted between September 25, 2002 and January 31, 2003. Each survey interview was approximately 35 minutes in length and all participants received a nominal $\$ 10$ incentive to participate in each wave. The Institutional Review Board of the New York Academy of Medicine reviewed and approved the study.

\section{Medsures}

During the baseline interview, we collected information on sociodemographic characteristics (age, gender, race/ethnicity, educational attainment, income, marital status), and September 11th event experiences (e.g., proximity to the WTC complex during the attacks). We as- sessed if the respondent experienced symptoms consistent with a panic attack in the first few hours after hearing about the September 11th attacks, based on the Diagnostic and Statistical Manual of Mental Disorders, Fourth Edition (DSM-IV; American Psychiatric Association, 1994) criteria for panic attacks. Also at baseline, we asked about lifetime traumatic event exposure (e.g., natural disaster, serious accident; Stamm, 1996), exposure to recent stressors (e.g., death of a spouse or close family member; Freedy, Kilpatrick, \& Resnick, 1993), and social support before the September 11th attacks. Subsequently, we assessed exposure to ongoing traumas and stressors at the first follow-up interview.

Eleven items related to the loss and gain of psychosocial resources were included in the first follow-up interview, assessing changes in resources in the year since September 11, 2001 (Norris, 2001). These resources were conceptually derived from Hobfoll's (1989; 1998) conservation of resources (COR) theory, and from the conservation of resources evaluation (COR-E; Hobfoll \& Lilly, 1993), with special application to the events of September 11. Respondents were instructed to report whether each of the following items had increased, decreased, or stayed the same since September 11th: time for adequate sleep, feeling valuable to others, free time, feeling that you are accomplishing your goals, time with loved ones, sense of optimism, sense of humor, feeling that you have control over your life, feeling that your life is peaceful, motivation to get things done, and feeling that your life has purpose. For each item, a loss variable (coded as 0 for no decrease, 1 for decreased a little, and 2 for decreased a lot) and a gain variable (coded as 0 for no increase, 1 for increased a little, and 2 for increased a lot) were created. The 11 items were summed to create a variable representing total loss of resources $(\alpha=.78)$, and likewise for the gain items $(\alpha=.78)$, with higher values indicating greater loss and gain, respectively. This measure was chosen because the National Institute of Mental Health recommended it for all research related to September 11th; hence, it could be used as a standard measure for comparison.

We used the National Women's Study (NWS) PTSD module (Kilpatrick et al., 1998) to assess probable PTSD 
symptoms since the September 11th terrorist attacks. The NWS PTSD module is a 17 -item measure of probable PTSD. It is used to evaluate the presence (yes/no) of Criterion $\mathrm{B}$ (reexperiencing, e.g., intrusive memories, distressing dreams), Criterion C (avoidance, e.g. efforts to avoid thoughts associated with the trauma, loss of interest in significant activities), and Criterion D (arousal, e.g. difficulty falling asleep or concentrating) symptoms. It also determines content for content-specific symptoms (e.g. content of dreams or nightmares), if symptom presence is endorsed. We assessed probable PTSD based on the presence of at least one reexperiencing symptom, at least three avoidance symptoms, and two arousal symptoms, reported for the period either between September 11, 2001, and the baseline interview or between the baseline and first follow-up interviews. Symptoms were not required to be related to the September 11th attacks.

Probable depression was assessed using the major depressive disorder scale from the nonpatient version of the Structured Clinical Interview for DSM III-R (Spitzer, Williams, \& Gibbon, 1987), adapted for use in telephone interviews. Following DSM-IV guidelines, respondents met criteria for probable depression if they had five or more of eight symptoms for at least 2 weeks, one of which was depressed mood or loss of pleasure or interest. The survey also asked the last time the respondent experienced these symptoms. The Cronbach's alpha for the eight symptoms used in this scale was 0.79 (Boscarino, Galea, Ahern, Resnick, \& Vlahov, 2002). Respondents meeting criteria for probable depression either between September 11, 2001, and the baseline interview or between the baseline and first follow-up interviews were classified as depressed since September 11th.

Results for depression in the past 30 days have been compared with those obtained by using the Brief Symptom Inventory-18 (BSI-18; Zabora et al., 2001) and showed the BSI-1 8 depression subscale had a sensitivity of $73 \%$ and a specificity of $87 \%$ in detecting depression as classified by our depression instrument (Boscarino et al., 2002). We did not assess either manic or psychotic symptoms; therefore, we could not further classify the disorder beyond probable major depression.

\section{Data Analusis}

We assessed the relation between key covariates, including the loss and gain of resources, and PTSD and probable depression since September 11th, using two-tailed chi-square tests for categorical variables and $t$ tests for continuous variables. All covariates significant in bivariate analyses at the $p<.05$ level were included in multivariable logistic regression models also adjusted for resource loss and gain. Sampling weights were calculated as the inverse probability of selection and applied to baseline data to correct for potential selection bias related to the number of household telephones, persons in the household, and oversampling of households in certain geographic areas; sampling weights to correct for potential nonresponse bias were applied to data from the first follow-up interview. We used SUDAAN software (Research Triangle Institute, 2001) to estimate standard errors and adjust analyses for the weighting.

\section{RESULTS}

We recruited 2,752 persons from the NYC metropolitan area at baseline; 1,939 persons also participated in the first follow-up interview, at which resource loss and gain were assessed. The population sampled was statistically comparable to the data from the U.S. Census (see Table 1). Furthermore, there were no statistically significant differences between characteristics of respondents in our baseline sample who did and did not participate in the first follow-up interview, in terms of both demographics and psychopathology (data not shown).

Table 2 shows the bivariate associations between resource loss and gain and probable PTSD and probable depression since September 11th. Mean resource loss since September 11th was significantly higher among those with probable PTSD and among those with probable depression. Participants with probable PTSD and probable depression did not report statistically greater levels of resource gain than those who did not meet criteria for probable PTSD or probable depression, respectively.

The unadjusted and adjusted relations between covariates and probable PTSD since September 11th are 
Table 1. Comparison of Sample Population with 2000 U.S. Census Data from the New York Metropolitan Area $(N=1939)$

\begin{tabular}{lccc}
\hline & $\begin{array}{c}\text { Weighted \% } \\
\text { from Sample }\end{array}$ & $\begin{array}{c}\text { \% from 2000 } \\
\text { U.S. Census }\end{array}$ & $\chi^{2 \dagger}$ \\
\hline Gender & & & \\
Male & 45.8 & 46.9 & 0.05 \\
Female & 54.3 & 53.1 & \\
Race/ethnicity & & & \\
$\quad$ White & 53.1 & 54.8 & 1.95 \\
African American & 16.7 & 16.5 & \\
Asian & 5.4 & 7.7 & \\
Hispanic & 20.6 & 18.5 & \\
Other & 4.2 & 2.6 & \\
Age & & & \\
18-24 & 13.7 & 11.7 & 3.26 \\
25-34 & 23.9 & 20.4 & \\
35-44 & 20.6 & 21.9 & \\
45-54 & 19.0 & 17.7 & \\
$55-64$ & 12.2 & 11.8 & \\
65+ & 10.6 & 16.5 & \\
\hline
\end{tabular}

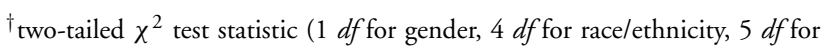
age).

presented in Table 3. Total loss of resources was associated with an increased risk of probable PTSD since September 11 th (odds ratio $[\mathrm{OR}]=1.22$ for every one point increase on the scale, $95 \%$ confidence interval $[\mathrm{CI}]=1.15-1.31$ ) even after adjusting for other covariates, including resource gain. As the odds ratio for resource loss is for each point on the scale, and the scale has marked variability, this indicates that difference in resource loss appreciably affects probable PTSD. Other significant predictors of probable PTSD since September 11th included experiencing a peri-event panic attack, traumatic events before September 11th, life stressors before and after September 11th, female gender, race/ethnicity, and marital status.

The unadjusted and adjusted relations between covariates and probable depression since September 11th are also presented in Table 3. Total loss of resources was associated with an increased risk of probable depression since September 11 th $(\mathrm{OR}=1.19$ for every one point increase on the scale, 95\% CI $=1.12-1.26)$ after adjusting for other covariates, including resource gain. Again, as the odds ratio
Table 2. Mean Loss and Gain of Resources, by PTSD and Depression Status, New York Metropolitan Area $(N=1939)$

\begin{tabular}{lcccccccc}
\hline & \multicolumn{3}{c}{ Resource Loss } & & \multicolumn{3}{c}{ Resource Gain ${ }^{\mathrm{b}}$} \\
\cline { 2 - 3 } \cline { 7 - 8 } & $M$ & $S D$ & $t$ & & $M$ & $S D$ & $t$ \\
\hline Total & 3.14 & 5.28 & & & 3.66 & 5.72 & \\
PTSD since & & & & & & \\
$\quad$ September 11 & & & & & & \\
$\quad$ No & 2.42 & 4.59 & $10.86^{*}$ & & 3.57 & 5.84 & 1.52 \\
$\quad$ Yes & 6.83 & 5.53 & & & 4.13 & 4.82 & \\
Depression since & & & & & & & \\
$\quad$ September 11 & & & & & & & \\
$\quad$ No & 2.49 & 4.52 & $9.93^{*}$ & & 3.58 & 6.17 & 1.53 \\
$\quad$ Yes & 6.35 & 5.41 & & & 4.09 & 4.53 & \\
\hline
\end{tabular}

${ }^{a}$ Sum of eleven individual loss items (alpha $=.78$ ); each item was coded as (0) no decrease, (1) decreased a little, (2) decreased a lot (range 0-22). ${ }^{\mathrm{b}}$ Sum of eleven individual gain items (alpha $=.78)$; each item was coded as (0) no increase, (1) increased a little, (2) increased a lot (range 0-22).

${ }^{*} p<.001$ (two-tailed t-test).

associated with resource loss is for each point on the scale, this effect is marked. Other significant predictors of probable depression since September 11th included experiencing a peri-event panic attack, being directly affected by the September 11th attacks, traumatic events after September 11th, life stressors before and after September 11th, and low social support.

\section{DISCUSSION}

Our findings largely confirmed the hypotheses regarding the relationship between resource loss and probable PTSD and probable depression, and support COR theory (Hobfoll, 1998; 2001) in relation to resource loss in the face of terrorism. The findings are similar to those found previously for the association of resource loss with psychological stress in response to disaster (Benight et al., 1999; Freedy et al., 1994; Norris \& Kaniasty, 1996; Sattler et al., 2002). Traumatic growth, viewed as resource gains in the domains of sense of meaning and intimacy, however, was not related to PTSD when controlling for other predictors. In contrast, resource loss was related to both greater probable PTSD and probable depression in the year following 
Table 3. Multivariable Models Predicting PTSD and Depression since September 11, New York Metropolitan Area $(N=1939)$

\begin{tabular}{|c|c|c|c|c|c|c|c|c|}
\hline & \multicolumn{4}{|c|}{ PTSD } & \multicolumn{4}{|c|}{ Depression } \\
\hline & \multicolumn{2}{|c|}{ Unadjusted } & \multicolumn{2}{|c|}{ Adjusted } & \multicolumn{2}{|c|}{ Unadjusted } & \multicolumn{2}{|c|}{ Adjusted } \\
\hline & OR & $95 \%$ CI & OR & $95 \% \mathrm{CI}$ & OR & $95 \% \mathrm{CI}$ & OR & $95 \% \mathrm{CI}$ \\
\hline Resource loss since September $11^{\text {a }}$ & $1.34^{* * *}$ & $1.26-1.42$ & $1.22^{* * *}$ & $1.15-1.31$ & $1.29^{* * *}$ & $1.22-1.35$ & $1.19^{* * *}$ & $1.12-1.26$ \\
\hline Resource gain since September $11^{\mathrm{b}}$ & 1.03 & $0.99-1.08$ & 1.04 & $0.98-1.11$ & 1.03 & $0.99-1.07$ & 1.02 & $0.97-1.08$ \\
\hline \multicolumn{9}{|c|}{ Lived below 14th Street on September 11} \\
\hline No & 1.00 & - & 1.00 & - & 1.00 & - & 1.00 & - \\
\hline Yes & $1.78^{* * *}$ & $1.31-2.41$ & 1.48 & $0.92-2.40$ & $1.47^{*}$ & $1.09-1.98$ & 1.11 & $0.73-1.68$ \\
\hline \multicolumn{9}{|l|}{ Peri-event panic attack } \\
\hline No & 1.00 & - & 1.00 & - & 1.00 & - & 1.00 & - \\
\hline Yes & $7.16^{* * *}$ & $4.79-10.71$ & $2.85^{* *}$ & $1.46-5.58$ & $5.48^{* * *}$ & $3.70-8.11$ & $2.08^{*}$ & $1.18-3.68$ \\
\hline \multicolumn{9}{|c|}{ Directly affected by September 11 attacks $^{c}$} \\
\hline No & 1.00 & - & 1.00 & - & 1.00 & - & 1.00 & - \\
\hline Yes & $2.19^{* * *}$ & $1.51-3.16$ & 1.44 & $0.82-2.54$ & $2.06^{* * *}$ & $1.45-2.92$ & $1.67^{*}$ & $1.05-2.65$ \\
\hline \multicolumn{9}{|l|}{ Traumatic events before September $11^{\mathrm{d}}$} \\
\hline 0 & 1.00 & - & 1.00 & - & 1.00 & - & 1.00 & - \\
\hline 1 & 0.95 & $0.53-1.72$ & 0.93 & $0.41-2.08$ & 0.91 & $0.55-1.50$ & 0.90 & $0.49-1.65$ \\
\hline $2-3$ & $2.28^{* *}$ & $1.33-3.93$ & 2.13 & $0.98-4.61$ & 1.27 & $0.78-2.08$ & 0.80 & $0.45-1.43$ \\
\hline $4+$ & $3.47^{* * *}$ & $1.98-6.09$ & 2.18 & $0.91-5.21$ & $3.13^{* * *}$ & $1.88-5.22$ & 1.52 & $0.79-2.90$ \\
\hline \multicolumn{9}{|l|}{ Traumatic events since September $11^{\mathrm{d}}$} \\
\hline 0 & 1.00 & - & 1.00 & - & 1.00 & - & 1.00 & - \\
\hline 1 & $2.37^{* * *}$ & $1.54-3.64$ & 1.24 & $0.68-2.28$ & $2.01^{* * *}$ & $1.34-3.02$ & 0.93 & $0.56-1.53$ \\
\hline $2+$ & $6.48^{* * *}$ & $4.07-10.32$ & 2.01 & $0.88-4.58$ & $7.32^{* * *}$ & $4.69-11.41$ & $2.65^{* *}$ & $1.32-5.32$ \\
\hline \multicolumn{9}{|l|}{ Life stressors before September $11^{\mathrm{e}}$} \\
\hline 0 & 1.00 & - & 1.00 & - & 1.00 & - & 1.00 & - \\
\hline 1 & $3.80^{* * *}$ & $2.48-5.83$ & $2.38^{* *}$ & $1.36-4.17$ & $2.08^{* * *}$ & $1.39-3.12$ & 1.08 & $0.66-1.77$ \\
\hline $2+$ & $8.62^{* * *}$ & $5.55-13.37$ & $3.15^{* *}$ & $1.49-6.64$ & $7.21^{* * *}$ & $4.69-11.09$ & $3.06^{* * *}$ & $1.71-5.50$ \\
\hline \multicolumn{9}{|l|}{ Life stressors since September $11^{\mathrm{e}}$} \\
\hline 0 & 1.00 & - & 1.00 & - & 1.00 & - & 1.00 & - \\
\hline 1 & $2.55^{* * *}$ & $1.56-4.15$ & 1.02 & $0.56-1.86$ & $3.08^{* * *}$ & $1.97-4.80$ & $1.86^{*}$ & $1.12-3.10$ \\
\hline $2+$ & $11.69^{* * *}$ & $7.33-18.63$ & $3.18^{* * *}$ & $1.66-6.13$ & $14.00^{* * *}$ & $9.08-21.59$ & $4.55^{* * *}$ & $2.53-8.20$ \\
\hline \multicolumn{9}{|c|}{ 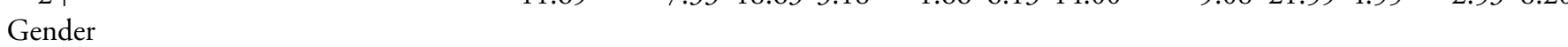 } \\
\hline Male & 1.00 & - & 1.00 & - & 1.00 & - & 1.00 & - \\
\hline Female & $2.11^{* * *}$ & $1.47-3.03$ & $2.16^{* *}$ & $1.32-3.53$ & $1.54^{*}$ & $1.09-2.17$ & 1.23 & $0.80-1.91$ \\
\hline \multicolumn{9}{|l|}{ Race/ethnicity } \\
\hline White & 1.00 & - & 1.00 & - & 1.00 & - & & \\
\hline Asian & 0.41 & $0.14-1.22$ & 0.35 & $0.10-1.21$ & 0.58 & $0.21-1.60$ & & \\
\hline Black & $1.89^{* *}$ & $1.22-2.90$ & 1.12 & $0.61-2.04$ & 1.52 & $0.99-2.33$ & & \\
\hline Hispanic & $2.84^{* * *}$ & $1.79-4.50$ & $2.26^{*}$ & $1.13-4.50$ & $1.69^{*}$ & $1.08-2.67$ & & \\
\hline Other & 1.82 & $0.84-3.93$ & 0.60 & $0.17-2.16$ & 1.33 & $0.59-2.99$ & & \\
\hline \multicolumn{9}{|l|}{ Educational attainment } \\
\hline Graduate work & 1.00 & - & 1.00 & - & 1.00 & - & 1.00 & - \\
\hline College degree & $1.92^{*}$ & $1.09-3.40$ & 1.63 & $0.77-3.49$ & 1.66 & $0.98-2.82$ & 1.32 & $0.68-2.59$ \\
\hline Some college & 1.63 & $0.90-2.96$ & 0.67 & $0.29-1.58$ & $2.18^{* *}$ & $1.27-3.74$ & 1.19 & $0.55-2.56$ \\
\hline HS/GED & $2.33^{* *}$ & $1.30-4.16$ & 0.97 & $0.42-2.24$ & $2.40^{* *}$ & $1.39-4.14$ & 1.30 & $0.60-2.78$ \\
\hline$<$ High school & $3.45^{* *}$ & $1.64-7.25$ & 1.17 & $0.41-3.32$ & $2.33^{*}$ & $1.13-4.81$ & 1.42 & $0.52-3.90$ \\
\hline
\end{tabular}


Table 3. Continued

\begin{tabular}{|c|c|c|c|c|c|c|c|c|}
\hline & \multicolumn{4}{|c|}{ PTSD } & \multicolumn{4}{|c|}{ Depression } \\
\hline & \multicolumn{2}{|c|}{ Unadjusted } & \multicolumn{2}{|c|}{ Adjusted } & \multicolumn{2}{|c|}{ Unadjusted } & \multicolumn{2}{|c|}{ Adjusted } \\
\hline & OR & $95 \% \mathrm{CI}$ & OR & $95 \% \mathrm{CI}$ & OR & $95 \% \mathrm{CI}$ & OR & $95 \% \mathrm{CI}$ \\
\hline \multicolumn{9}{|l|}{ Marital status } \\
\hline Married & 1.00 & - & 1.00 & - & 1.00 & - & 1.00 & - \\
\hline Divorced/Separated/Widowed & $3.15^{* * *}$ & $2.00-4.95$ & 1.72 & $0.94-3.14$ & $1.83^{* *}$ & $1.21-2.76$ & 0.90 & $0.53-1.54$ \\
\hline $\begin{array}{l}\text { Never married/Unmarried couple } \\
\text { Income at baseline }\end{array}$ & $2.21^{* * *}$ & $1.47-3.32$ & $2.16^{* *}$ & $1.27-3.68$ & $1.76^{* *}$ & $1.20-2.59$ & 1.61 & $0.98-2.64$ \\
\hline$\$ 100,000+$ & 1.00 & - & 1.00 & - & 1.00 & - & 1.00 & - \\
\hline$\$ 75,000-\$ 99,999$ & $3.03^{* *}$ & $1.43-6.42$ & 1.93 & $0.75-4.98$ & 1.25 & $0.64-2.47$ & 0.78 & $0.33-1.84$ \\
\hline$\$ 50,000-\$ 74,999$ & $2.36^{*}$ & $1.16-4.82$ & 1.09 & $0.45-2.61$ & 1.33 & $0.71-2.48$ & 0.75 & $0.36-1.58$ \\
\hline$\$ 40,000-\$ 49,999$ & $7.42^{* * *}$ & $3.27-16.83$ & $2.76^{*}$ & $1.02-7.48$ & $3.24^{* * *}$ & $1.62-6.48$ & 1.73 & $0.67-4.50$ \\
\hline$\$ 30,000-\$ 39,999$ & $5.54^{* * *}$ & $2.70-11.37$ & 1.75 & $0.71-4.32$ & $3.78^{* *}$ & $1.48-5.22$ & 1.27 & $0.59-2.73$ \\
\hline$\$ 20,000-\$ 29,999$ & $6.92^{* * *}$ & $3.32-14.41$ & $2.89^{*}$ & $1.14-7.31$ & $3.05^{* * *}$ & $1.61-5.77$ & 1.64 & $0.77-3.49$ \\
\hline$<\$ 20,000$ & $8.12^{* * *}$ & $3.96-16.64$ & 2.07 & $0.86-5.02$ & $3.20^{* * *}$ & $1.75-5.87$ & 1.27 & $0.58-2.78$ \\
\hline \multicolumn{9}{|l|}{ Social support before September 11} \\
\hline High & 1.00 & - & 1.00 & - & 1.00 & - & 1.00 & - \\
\hline Medium & $2.06^{* *}$ & $1.28-3.33$ & 1.62 & $0.85-3.12$ & 1.32 & $0.86-2.02$ & 1.00 & $0.58-1.71$ \\
\hline Low & $2.38^{* * *}$ & $1.53-3.71$ & 1.60 & $0.86-3.00$ & $2.14^{* * *}$ & $1.45-3.15$ & $1.87^{*}$ & $1.13-3.11$ \\
\hline
\end{tabular}

${ }^{a}$ Sum of eleven individual loss items (alpha $=.78$ ); each item was coded as (0) no decrease, (1) decreased a little, (2) decreased a lot (range 0-22). Odds ratios associated with resource loss and gain are for each point change on the scale. ${ }^{b}$ Sum of eleven individual gain items (alpha $\left.=.78\right)$; each item was coded as $(0)$ no increase, (1) increased a little, (2) increased a lot (range 0-22). Odds ratios associated with resource loss are for each point change on the scale. ${ }^{c}$ Directly affected" includes persons who were in the WTC complex during the attacks, were injured during the attacks, lost possessions or property, had a friend or relative killed, lost a job as a result of the attacks, or were involved in the rescue efforts. " "Traumatic events" include natural disaster; a serious accident at work, in a car, or somewhere else; being attacked with or without a weapon; unwanted sexual contact; other situations resulting in injury; situations in which the respondent feared being

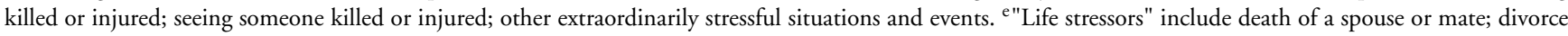
or separation; death of a close family member; serious injury or illness; marriage; family problems with spouse or child; problems at work; mental or emotional problems.

${ }^{*} p<.05 .{ }^{* *} p<.01 .{ }^{* * *} p<.001$.

the September 11th attack on those in the NYC metropoli$\tan$ area. These findings were robust after controlling for other important predictors, indicating that resource loss is a key independent predictor of post-terrorism probable PTSD and probable depression risk. These findings are especially convincing given that our analyses controlled for peri-traumatic panic attacks, experience of other stressors, and prior trauma. That loss of resources was a robust predictor, controlling for these elements, strongly suggests that it is resource loss and not a generalized negative or pathological responding tendency that is responsible for the resource loss factors' predictive power.

In addition, as predicted by COR theory, resource loss was a much more important predictor of probable PTSD and probable depression than was resource gain. This supports an important principle of COR theory that suggests that resource loss is central and that resource gain does relatively little to offset or limit the impact of resource loss and exposure to trauma. As resource loss includes both tangible (e.g., economic) and perceived (e.g., sense of hope) resources, both objective and perceived resource losses appear important. This suggests that exposure to terrorism begins a cascade of losses that bridge material, personal, and interpersonal domains of people's lives and that each of these domains may play a deleterious role in the lives of those affected. We should also underscore that because we relied on self-report, even material resource losses must be seen as having an appraised element. Those who can 
sustain their armamentarium of resources may be more likely to retain their sense of coping efficacy and, in turn, limit their psychological distress (Benight et al.,1999).

Although we did not find traumatic growth to have a negative impact, it did not have a protective effect on risk for probable PTSD and depression either. This is unlikely to be attributed to our using a different scale than that developed by Tedeschi and Calhoun (1995). Their scale is longer, but has very similar items reflecting relating to others, personal strength, and spiritual change. Indeed, many studies that have examined the psychological correlates of traumatic growth fail to find beneficial effects. The lack of positive findings here and elsewhere (Elder \& Clipp, 1988; Hobfoll et al., 2006; Lehman et al., 1993; Park, Cohen, \& Murch, 1996; Tomich \& Helgeson, 2004; Wild $\&$ Paivio, 2003) for resource gains that have been associated with traumatic growth indicates a need for careful qualification of this area of trauma intervention (Tedeschi \& Calhoun, 1995, 2004) and its course in development of posttraumatic well being.

Tedeschi and Calhoun $(1995,2004)$ have argued that traumatic growth is a benefit in its own right, as it allows those who have experienced trauma to see "some good emerging from their struggle" (Tedeschi \& Calhoun, 1996, p. 455). However, if we look at the correlates of traumatic growth, a different picture emerges, in at least some instances. Hobfoll et al. (2006) found traumatic growth to be related to greater PTSD and depression, as well as to greater xenophobia and support for extreme political violence among those exposed to terrorism and war. Similarly, among cancer victims, greater traumatic growth was related to poorer outcomes (Tomich \& Helgeson, 2004). Finding an unseen benefit in trauma may be less advantageous than has been advocated. In certain instances at least, it may interfere with efforts to get past the trauma and to move on with the business of living. In this regard, traumatic growth has been associated with greater rumination (Calhoun, Cann, Tedeschi, \& McMillan, 2000) and research on depression has found such rumination to be related to worse outcomes, in contrast to focusing on future directness and active coping (Addis \& Carpenter, 1999). It is also possible that reports of traumatic growth are actually post facto attempts by individuals to derogate past selves through self-enhancement to maintain positive views of their current selves, rather than indications of actual personal growth (Ross, 1989; Wilson \& Ross, 2001).

With some studies finding positive outcomes associated with traumatic growth whereas others do not, it will be important to explore whether the impact of traumatic growth is related to timing, as traumatic growth may be beneficial at some posttrauma periods and not others. We are also exploring whether traumatic growth actions (e.g., dedicating time to help others, being with loved ones more) may have a positive impact, whereas only having the associated cognitions may be deleterious. Finally, it is possible that posttraumatic growth interacts with prior personal vulnerability and resiliency, such that those who are psychologically more resilient at the outset use posttraumatic growth in a positive fashion, whereas those with prior psychological vulnerability misuse it. Clearly, more will need to be studied in this regard and prospective study will be critical.

This study has both strengths and limitations. It is a large sample that we followed prospectively, represents several ethnic groups and had good representation of those potentially impacted by a major traumatic event. Moreover, we conducted a highly conservative test of COR theory by controlling for major predictors of traumatic distress, and we argue that by controlling for these factors we remove many of the usual confounds of self-report relating to a generalized or pathological reporting style. Although it is difficult in research on terrorism and disasters to obtain preevent interviews, such controls add to an argument for assigning causal order such that resource loss predicts greater likelihood of depression and PTSD. Nevertheless, we cannot say that the experience of resource loss causes PTSD or depression, only that resource loss is a strong predictor of these markers of psychological distress. Other limitations include use of retrospective reporting (which may be affected by recall biases), use of abbreviated scales, and our ability to assess only probable depression and PTSD and not a clearly diagnosable disorder. However, we note that it is the nature of large-scale surveys such 
as these to rely on such methods and measures. Telephone surveys are often criticized for having response rates that are lower than are those in typical in-person epidemiologic assessments. However, telephone surveys have both strengths and limitations, and have been shown to compare favorably to in-person surveys in studies of community health status (Aneshensel, Frerichs, Clark, \& Yokopenic, 1982). Finally, we did not assess prior psychiatric history; therefore, we cannot rule out the explanation that those who are more emotionally vulnerable are more likely to be vulnerable to resource loss when facing traumatic stress (Brewin et al., 2000).

Our findings have important clinical implications. Most of the predictors of posttraumatic outcomes, such as prior mental health, prior exposure to stressors and trauma, peritraumatic reactions, and direct effects of the trauma are "water under the bridge." Resource loss patterns, in contrast, occur after trauma and are potentially amenable to intervention through individual treatment, group intervention efforts, and community interventions. Hence, our results indicate avenues that interventions can focus upon. Efforts can be directed to shore up loss sequences in the self, social, and environmental support realms to prevent PTSD and depression and limit their continuation after their onset. Hence, a focus on breaking loss cycles and helping people to initiate gain cycles should be considered in both individual interventions and preventive, broadbased community efforts.

Overall, our findings suggest the critical role of resource loss in predicting PTSD and depression following exposure to terrorism. This supports findings from disaster research that similarly has found resource loss to be among the key predictors of the course of posttraumatic emotional reactions (Ironson et al., 1997; Norris \& Kaniasty, 1996; Sattler et al., 2002). This means that rather than seeing psychosocial and material resources as static predictors of PTSD and depression, they should be understood as factors that may change when people are confronted with terrorism or disasters. This, in turn, results in likely resource loss-emotional distress cycles that will cascade and gain negative momentum if intervention does not act to halt these cycles.

\section{REFERENCES}

Addis, M. E., \& Carpenter, K. M. (1999). Why, why, why? Reasongiving and rumination as predictors of response to activation and insight-oriented treatment rationales. Journal of Clinical Psychology, 55, 881-894.

Ai, A. L., Cascio, T., Santangelo, L. K., \& Evans-Campbell, T. (2005). Hope, meaning, and growth following the September 11,2001 , terrorist attacks. Journal of Interpersonal Violence, 20, 523-548.

American Psychiatric Association. (1994). Diagnostic and statistical manual of mental disorders (4th ed). Washington, DC: Author.

Aneshensel, C. S., Frerichs, R. R., Clark, V. A., \& Yokopenic, P. A. (1982). Telephone versus in-person surveys of community health status. American Journal of Public Health, 72, 1017-1021.

Benight, C.C., Ironson, G., Klebe, K., Carver, C. S., Wynings, C., Burnett, K., et al. (1999). Conservation of resources and coping self-efficiacy predicting distress following a natural disaster: A causal model analysis where the environment meets the mind. Anxiety, Stress, and Coping, 12, 107-126.

Boscarino, J. A., Galea, S., Ahern, J., Resnick, H., \& Vlahov, D. (2002). Utilization of mental health services following the September 11th terrorist attacks in Manhattan, NYC. International Journal of Emergency Mental Health, 4, 143155 .

Breslau, N., Davis, G. C., Andreski, P., Peterson, E. L., \& Schultz, L. R. (1997). Sex differences in posttraumatic stress disorder. Archives of General Psychiatry, 54, 1044-1048.

Brewin, C. R., Andrews, B., \& Valentine, J. D. (2000). Meta-analysis of risk factors for posttraumatic stress disorder in trauma-exposed adults. Journal of Consulting and Clinical Psychology, 68, 748766.

Bryant, R. A., \& Harvey, A. G. (2003). Gender differences in the relationship between acute stress disorder and posttraumatic stress disorder following motor vehicle accidents. Australian and New Zealand Journal of Psychiatry, 37, 226-229.

Calhoun, L. G., Cann, A., Tedeschi, R. G., \& McMillan, J. (2000). A correlational test of the relationship between posttraumatic growth, religion, and cognitive processing. Journal of Traumatic Stress, 13, 521-527.

Diener, E., \& Fujita, F. (1995). Resources, personal strivings, and subjective well-being: A nomothetic and idiographic approach. Journal of Personality and Social Psychology, 68, 926935.

Dohrenwend, B. P., \& Dohrenwend, B. S. (1981). Socioenvironmental factors, stress, and psychopathology. Part 1. Quasiexperimental evidence on the social causation-social selection 
issue posed by class differences. American Journal of Community Psychology, 9, 129-146.

Dohrenwend, B. P., Raphael, K. G., Schwartz, S., Stueve, A., \& Skodol, A. (1993). The structured event probe and narrative rating method for measuring stressful life events. In L. Goldberger \& S. Breznitz (Eds.), Handbook of stress: Theoretical and clinical aspects (pp. 174-199). New York: The Free Press.

Elder, G. H., \& Clipp, E. C. (1988). Combat experience, comradeship, and psychological health. In J. P. Wilson, Z. Harel, \& B. Kahanna (Eds.), Human adaptation to extreme stress: From the Holocaust to Vietnam (pp. 131-156). New York: Plenum.

Franklin, C. L., Young, D., \& Zimmerman, M. (2002). Psychiatric patients' vulnerability in the wake of the September 11 th terrorist attacks. Journal of Nervous and Mental Disease, 190, 833-838.

Frazier, P., Conlon, A., \& Glaser, T. (2001). Positive and negative life changes following sexual assault. Journal of Consulting \& Clinical Psychology, 69, 1048-1055.

Freedy, J. R., Kilpatrick, D. G., \& Resnick, H. S. (1993). Natural disasters and mental health: Theory, assessment, and intervention. In R. Allen (Ed.), Handbook of post-disaster interventions [Special issue]. Journal of Social Behavior and Personality, 8(5), 49-103.

Freedy, J. R., Saladin, M. E., Kilpatrick, D. G., Resnick, H. S., \& Saunders, B. E. (1994). Understanding acute psychological distress following natural disaster. Journal of Traumatic Stress, 7 , 257-273.

Galea, S., Ahern, J., Resnick, H., Kilpatrick, D., Bucuvalas, M., Gold, J., et al. (2002). Psychological sequelae of the September 11 terrorist attacks in New York City. New England Journal of Medicine, 346, 982-987.

Galea, S., Vlahov, D., Resnick, H., Ahern, J. Susser, E., Gold, J., et al. (2003). Trends of probable post-traumatic stress disorder in New York City after the September 11 terrorist attacks. American Journal of Epidemiology, 158, 514-524.

Galea, S., Vlahov, D., Tracy, M., Hoover, D., Resnick, H., \& Kilpatrick, D. G. (2004). Hispanic ethnicity and post-traumatic stress disorder after a disaster: Evidence from a general population survey after September 11. Annals of Epidemiology, 14, 520-531.

Hobfoll, S. E. (1988). The ecology of stress. New York: Hemisphere.

Hobfoll, S. E. (1989). Conservation of resources: A new attempt at conceptualizing stress. American Psychologist, 44, 513-524.

Hobfoll, S. E. (1998). Stress, culture, and community: The psychology and philosophy of stress. New York: Plenum.
Hobfoll, S.E. (2001). The influence of culture, community, and the nested-self in the stress process: Advancing conservation of resources theory. Applied Psychology, 50, 337-370.

Hobfoll, S. E., Canetti-Nisim, D., \& Johnson, R. J. (2006). Exposure to terrorism, stress-related mental health symptoms, and defensive coping among Jews and Arabs in Israel. Journal of Consulting and Clinical Psychology, 74, 207-218.

Hobfoll, S. E. \& Lilly, R. (1993). Resource conservation as a strategy for community psychology. Journal of Community Psychology, $21,128-148$.

Hobfoll, S. E., Lomranz, J., Eyal, N., Bridges, A., \& Tzemach, M. (1989). Pulse of a nation: Depressive mood reactions of Israelis to the Israel-Lebanon War. Journal of Personality and Social Psychology, 56, 1002-1012.

Ironson, G., Wynings, C., Schneiderman, N., Baum, A., Rodriguez, M., Greenwood, D., et al. (1997). Posttraumatic stress symptoms, intrusive thoughts, loss, and immune function after Hurricane Andrew. Psychosomatic Medicine, 59, 128141.

Kilpatrick, D. G., Resnick, H. S., Freedy, J. R., Pelcovitz, D., Resick, P. A., Roth, S., et al. (1998). The posttraumatic stress disorder field trial: Evaluation of the PTSD construct-criteria A through E. In T. A. Widiger, A. J. Frances, H. A. Pincus, M. B. First, R. Ross, \& W. Davis (Eds.), DSM-IV sourcebook (Vol. 4, pp. 803-844). Washington, DC: American Psychiatric Association.

King, D. W., King, L. A., Foy, D. W., Keane, T. M., \& Fairbank, J. A. (1999). Posttraumatic stress disorder in a national sample of female and male Vietnam veterans: Risk factors, war-zone stressors, and resilience-recovery variables. Journal of Abnormal Psychology, 108, 164-170.

Lazarus, R. S., \& Folkman, S. (1984). Stress, appraisal, and coping. New York: Springer.

Lehman, D. R., Davis, C. G., DeLongis, A., Wortman, C. B., Bluck, S., Mandel, D. R., et al. (1993). Positive and negative life changes following bereavement and their relations to adjustment. Journal of Social and Clinical Psychology, 12, 90-112.

Lomranz, J., Hobfoll, S. E., Johnson, R. J., Eyal, N., \& Zemach, M. (1994). A nation's response to attack: Israelis' depressive reactions to the Gulf War. Journal of Traumatic Stress, 7, 5963.

New York City Department of Health and Mental Hygiene. (2003). Summary of vital statistics 2002: The City of New York. Retrieved January 25, 2004 from www.nyc.gov/html/ doh/downloads/pdf/vs/2002sum.pdf 
New York City Office of the Comptroller. (2002). One year later: The fiscal impact of 9/11 on New York City. Retrieved January 25, 2004 from www.comptroller.nyc.gov/bureaus/ bud/reports/impact-9-11-year-later.pdf

Nixon, R. D. V., Resick, P. A., \& Griffin, M. G. (2004). Panic following trauma: The etiology of acute posttraumatic arousal. Journal of Anxiety Disorders, 18, 193-210.

Norris, F. H. (2001). Measuring exposure to the events of September 11, 2001: Pretest results and stress/loss norms obtained from a minimally exposed diverse sample of college students [Data file]. Available from the National Institutes of Health, Office of Behavioral and Social Sciences Research Web site, http://obssr.od.nih.gov/activities/911/attack.htm

Norris, F. H., Baker, C. K., Murphy, A. D., \& Kaniasty, K. (2005). Social support mobilization and deterioration after Mexico's 1999 flood: Effects of context, gender, and time. American Journal of Community Psychology, 36, 15-28.

Norris, F. H., \& Kaniasty, K. (1996). Received and perceived social support in times of stress: A test of the social support deterioration deterrence model. Journal of Personality and Social Psychology, 71, 498-511.

Park, C. L., Cohen, L. H., \& Murch, R. L. (1996). Assessment and prediction of stress-related growth. Journal of Personality, 64, 71-105.

Research Triangle Institute. (2001). SUDAAN user's manual (Version 8.0). Research Triangle Park, NC: Author.

Ross, M. (1989). Relation of implicit theories to the construction of personal histories. Psychological Review, 96, 341-357.

Sattler, D. N., Preston, A. J., Kaiser, C. F., Olivera, V. E., Valdez, J., \& Schlueter, S. (2002). Hurricane Georges: A cross-national study examining preparedness, resource loss, and psychological distress in the U.S. Virgin Islands, Puerto Rico, Dominican Republic, and the United States. Journal of Traumatic Stress, 15, 339350 .

Schlenger, W., Cadell, J., Ebert, L., Jordan, B., Rourke, K., Wilson, D., et al. (2002). Psychological reactions to terrorist attacks: Findings from the National Study of Americans' Reactions to
September 11. Journal of the American Medical Association, 288, 581-588.

Spitzer, R. L., Williams, J. B., \& Gibbon, M. (1987). Structured Clinical Interview for DSM-III-R-non-patient version. New York: New York State Psychiatric Institute, Biometrics Research Department.

Stamm, B. H. (1996). Contextualizing death and trauma: A preliminary endeavor. In C. R. Figley (Ed.), Death and trauma (pp. 3-21). New York: Brunner/Mazel.

Tedeschi, R. G., \& Calhoun, L. G. (1995). Trauma \& transformation: Growing in the aftermath of suffering. Thousand Oaks, CA: Sage.

Tedeschi, R. G., \& Calhoun, L. G. (1996). The Posttraumatic Growth Inventory: Measuring the positive legacy of trauma. Journal of Traumatic Stress, 9, 455-471.

Tedeschi, R. G., \& Calhoun, L. G. (2004). Posttraumatic growth: Conceptual foundations and empirical evidence. Psychological Inquiry, 15, 1-18.

Tomich, P. L., \& Helgeson, S. (2004). Is finding something good in the bad always good? Benefit finding among women with breast cancer. Health Psychology, 23, 16-23.

Wells, J. D., Hobfoll, S. E., \& Lavin, J. (1999). When it rains it pours: The greater impact of resource loss compared to gain on psychological distress. Personality and Social Psychology Bulletin, 25, 1172-1182.

Wild, N. D., \& Paivio, S. C. (2003). Psychological adjustment, coping, and emotion regulation as predictors of posttraumatic growth. Journal of Aggression, Maltreatment \& Trauma, 8(4), 97-122.

Wilson, A. E., \& Ross, M. (2001). From chump to champ: People's appraisals of their earlier and present selves. Journal of Personality \& Social Psychology, 80, 572-584.

Zabora, J., BrintzenhofeSzoc, K., Jacobsen, P., Curbow, B., Piantadosi, S., Hooker, C., et al. (2001). A new psychosocial screening instrument for use with cancer patients. Psychosomatics, 42, 241-246. 